\title{
AN EMPIRICAL STUDY ON THE EFFECT OF BUSINESS ETHICS
}

\section{ON THE COMPANY'S CSR PRACTICES}

\author{
N. K. GUPTA ${ }^{1} \&$ JYOTI KASANA ${ }^{2}$ \\ ${ }^{1}$ Associate Professor, Ramjas College, University of Delhi, India \\ ${ }^{2}$ Assistant Professor, Rajdhani College, University of Delhi, India
}

\begin{abstract}
Ethics word comes from the Greek word "ethos", which means explaining an individual and community both. In general, it's not just mean that it involves only legal framework, such standards made by company, adhering concerning their promises and following general rules of not say lie, be honest, loyal and respect for everyone. CSR means the accountability of an organisation towards its all stakeholders consists of customers, employees, shareholders, creditors, suppliers and all person who are directly or indirectly associated with a business entity. The present study's intention is to assess the effect of Business Ethics on corporate social responsibility practices with the help of some identified factors of these variables. Business Ethics has two factors and Corporate Social Responsibility practices has nine factors, which have been selected after pilot study, experts suggestions and exhaustive literature review. To evaluate this, a sample of 335 employees who are working in telecom companies situated in Delhi and NCR region was collected through structured questionnaire. Data was collected from small and large level companies and level has been decided on the basis of company's employee strength. Data collected in the period from September 2015 to June 2016. To analyse data different statistical tools like average, Spearman's Rank Correlation, Regression analysis.

KEYWORDS: Business Ethics, Corporate Social Responsibility, Telecom Companies, Spearman's Rank Correlation, Regression Analysis \& Chi-Square Test
\end{abstract}

Received: Oct 06, 2017; Accepted: Oct 26, 2017; Published: Nov 21, 2017; Paper Id.: IJBMRDEC20173

\section{INTRODUCTION}

India is a country of diversity with different cultures and organisations should consider this diversity which comprises code of ethics for companies. Ethics and business are corrected terms which cannot work in isolation. Ethics needs a community or business and vice versa. Ethics tell what is right or wrong. In today's era ethics are the necessity of every business concern and it also enlightens phenomenon of CSR practices. The inevitability arises for the proper formulation of strategies which makes ethical values more significant in business practices, implementation of strategies and good practices in business activities. Robin, Donald and Reindenbach (1987) ${ }^{1}$ positive relationship, have been found in organisational commitment and corporate ethical values (Hunt, Shelby, Wood, Van and Chonko (1989) ${ }^{2}$. To imitate ethics in corporation and for the development of organisation, White Louis and Rhodeback ${ }^{3}$ suggested cross-cultural education in school's fusion of ethics codes for professions and proper training, for students and practitioners about ethical values. 
Ethics and values are interrelated but somehow different terms. Ethics is like a set of actions and it develops from the beliefs and attitudes of an individual have. On the other side, values are conceptual in nature which means the told set of beliefs which turns into actions or behaviour. "CSR is nothing more than smart management cloaked in the language of morality and ethics”. (Reich 2007) Ethics and CSR is relative concepts. Ethics are considered as internal in nature and deals with the eternal issues of stakeholders in organisation while social responsibilities deal with the external environment of the organisation and emphasis on the wider issues of society and communities. Verbal assurance is not the key of success from the stakeholders view and to get the trust of societies. Business ethics are the codes of principal and value. Employee's decisions and actions of a company enable it to know the difference between right/wrong or good/bad evaluation in decision making process and also enriches organisation to choose or select the decision which is ethically right. It can be used to explain the action of an individual/ group or organisation. Two different theories describe business ethics in two different ways: Shareholders perspective and stakeholder's perspective. Shareholder perspective explains the decisions regarding owners wealth are always right and should be only adhere to the interest of investors decision regarding companies policies need to maximize value of the owners and enables organisation to avail opportunities for the profitable engagement. In contrast of shareholder perspective, stakeholder's perspective is the notion of CSR which stabilize a sense of belongingness in stakeholder for organisation with the help of aggressive decisions which satisfies the urge and interest of all stakeholders unlike shareholder perspective which concentrates only to maximize financial stakeholder values. The idea behind this concept is to bring every stakeholder in an equal place and to take decisions which are in favour of ethical right thing and also make business successful and robust. "Business ethics can be understood as a comprehensive study of corporate policies which cannot be viewed as an outlying concept". The concreteness of corporate social responsibility comes from the company's ethicality which is an obligation and it enables an organisation to ascertain the influence of decision and actions on the society and organisation as well. (Davis and Blomstrom, 1971) It is evident that, ethical behaviour of an organisation strengths its culture, as well as it enhances leadership of a company in the growth of main ethical ideas and values. Corporate Social Responsibility came into usage in 1990's, as a corporate social and environmental responsibility. - The term CSR, on the other hand, is usually taken to include environmental, social and human rights-based impacts and initiatives of companies (Ward and Fox 2002), and in many countries-both industrialized and developing-the concept and practices are taken seriously (Hopkins 2003). Corporate social responsibility is a very big word to understand, it entail of all social responsibilities which has to be fulfilled by the companies for the sake of whole society. CSR means the accountability of an organisation towards its all stakeholders comprises of customers, employees, shareholders, creditors, suppliers and all person who are directly or indirectly associated with a business entity. It is a commitment of a corporation to do systematic consideration of the social, ethical, environmental and cultural dimensions of their operations. The term - Charity and - Philanthropy were widespread in the companies, before the concept of Corporate Social Responsibility came into existence or common usage in the 1990s. CSR has been defined in many ways and each definition, explanation or interpretation imitates the context, values, ethics and ideologies of the defining agencies and it changes according to the time and place, where corporates acts to be socially responsible. According to Business and Social Responsibility (BSR) CSR is defined as - achieving commercial success in ways that honour ethical values and respect people, communities and the natural environmentll. (BSR 2003). Companies will necessarily have to take into account cultural differences and ethical practices when defining the CSR policies and communicating to organizational members (Bird Smueker, 2007). 


\section{Business Ethics Theory of Corporate Social Responsibility}

It is a theory of business ethics with Corporate Social Responsibility which covers extensive scope of social obligations and their moral ethics and duties towards communities and societies (Bigg, 2004). This theory explains three inter-related, but somehow diverted ethics.

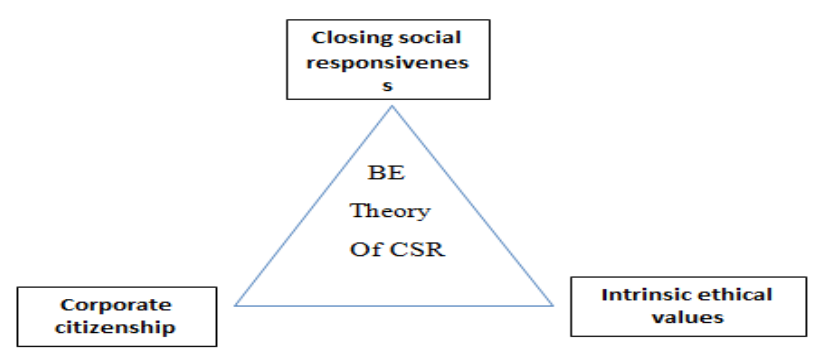

Figure 1: Corporate Social Responsibility Ethical Grounds (Source: Bigg, 2004)

It is stated that, acceptance of change in any field is required. Emerging issues are coming day by day, which should be adopted and accepted by the firms because, societies are the necessity of every firm and companies should understand their responsibility to do remedy of any social problems and fulfil expectations of communities as well.

Intrinsic ethical values are also known as eternal ethical values which based on a universal principle that every organisation should be fair always and not be biased in any case. Social justice and human rights should be on priority for firms. Corporate citizenship explains the better role of corporates to be a citizen of the country as well as society, which adheres organisations to take initiatives for the well-being of society as a part of it. This theory shows that corporate social responsibility is more as philanthropic and ethical based concept instead of legitimate and economic concept.

\section{REVIEW OF LITERATURE}

Ethics and Business are two correlated terms which cannot work in isolation Ethics needs any community or Business simultaneously business, needs to adhere with Ethics. Ethics tell what is wrong or right. Now days, Ethics is the necessity of every business and it explores the phenomenon of corporate social responsibility also.

Robin, Donald and Reindenbach, (1987) propagated the conceptual idea about ethics and corporate social responsibility. Study concentrated to the theoretical facets of both field and found the similarities and differences amongst CSR and ethics. It found that there is a gap between the phenomenon of corporate social responsibility and its business practices and also emphasized on the gap between the Business ethics research and corporate social responsibility research. Study suggested the need of proper formulation of strategies which makes organisational culture and ethical values more significant in business practices and implementation of strategies and good practices in business activities. Hunt, Shelby, Wood, Van and Chonko (1989) investigated the concept of organisational commitment and corporate ethical values. It ensured the relationship between both the concepts. Study explored the mutual relationship, among the corporate ethics and organisational commitment. Hypothesis was made to analyse the objective of the study that, organisational commitment is related to corporate ethical values explore the relationship between corporate ethical values and organizational commitment towards society. Data was analysed with the help of correlation analysis between the study variables. Results are very interesting that there is a significant positive relationship between organisational commitments towards society. White, Louis \& Rhodeback (1992) explored the arena of cross-cultural organisational development, which can be put to halt because of ethical misperception. So, study endeavoured an analysis of cross-cultural in 
organisational development and found out the reasons for ethical dilemmas, related to cross culture. Empirical study was carried out and primary data included two samples, collected through few business students of United States and Taiwan. Data was analysed through MNOVA (Multivariate analysis of variance) statistical tool, which revealed that, there is a significant cultural difference in the perception of ethics. Ethicality Rating of United States respondents was higher, as compared to Taiwanese respondents. Result of the study suggested that, there must be cross-cultural education in every school, fusion of ethics codes for professions also and there should be proper ethical training for students, as well as practitioners. Dunfee, Thomas, Smith, Craig and Ross (1998) developed a "normative moral foundation called Interpretive Social Contractors Theory (ISCT)". Study investigated that, how Interpretive Social Contractors theory offers a structure, which can solve the problems that arise because of different cultures in the industry on ethics. Application of Interpretive Social Contractors theory has been developed, to understand the notion of cross-culture and those ethical decisions which are mandatory, for the harmonious future of any organisation. Study gave one example of this application was bribery. Martin (2000) explored the term innovation, business \& ethics and said innovation always carried ethical implication and explained the ethics of innovation, which tells the key rules of innovation and they guide managers to take decisions while they are indulge in the process of innovation for their organisation and community. Author mentioned the rules of innovation. For community, innovations are new, Innovation affects people and it is affected by people Innovations disrupted the natural concepts, Innovations are shared responsibility of communities and innovative firm, Continuous modification is required for successful innovations, Features of an innovation matters a lot. These rules have been applied to assess the Google Inc. in China. Study represented innovators as matchmakers and innovation as novel. It introduced a technology from which users are not familiar. It highlighted the shared responsibility of community and innovators. Study suggested that business has a very important role in innovation for communities and lastly Ethical innovation accelerates sustainable advantage for companies and creating positive relationship between communitytechnology. Altham (2002) investigated the concept of Corporate Ethics which involves two fields Business Ethics and Corporate social Responsibility. Study presented Business Ethics contrasted with Corporate Social Responsibility. Study pointed out the four areas of dissimilarity in favour of the statement that how Corporate social Responsibility differs from Business Ethics. This research is based on the question that are these approaches competing or complementary? Study unfolds the relationship between these factors on some criteria: 1) relation of any field to regulation 2) Nature of approach that each deploy -responsive or pre-emptive 3) through stakeholders identification 4) discussion on the enlargement of responsibility to stakeholders.

Study concluded that every company should have the sound business policies which can maintain the decorum and synchronization of the business, so to develop strategies and survival in today's competitive world, every organisation should indulge in the process of corporate social responsibility and business ethics to decipher the issue of corporate ethics. Donaldson \& Fafaliou (2003) investigated the similarities and differences between the three movements such as: Corporate Social Responsibility, Corporate Governance and Business Ethics and also provided a summary analysis which is based on the belief that business is as an ideology and it could get benefit from the introduction of the role of business and management. Author explained the term business ethics into two different terms namely; "Ethics I" and "Ethics II" in which Ethics-I related to conventional ethics and Ethics-II related to evaluative ethics. Author raised some issues related to business ethics such as: Relativism, Subjectivism and Objectivism. Relativism related to time and place. In this, one thing is obligatory in one country but it is immortal in another country. Subjectivism says that values are the perception or matter of persons taste and choice. Objectivism is contradicted to above two approaches that there should be some values which 
are not dependent upon country and time or individual perception. These values should be based upon the moral values such as; doing good, not harming anyone, not telling lie, keeping promises etc. The notion of CSR has been discussed and the theoretical framework of CSR explained with the help of definitional aspects. Author has explained the concept of corporate and governance respectively. Corporate "As a body of persons especially one authorised to act as an individual". Governance "as act, manner, fact or function of governing sway or control". Study concluded that there is a gap between the real world and the codes of practice made for corporate governance, business ethics and corporate social responsibility for companies, so the practical implications of codes could reduce the gap and can benefited to the business as well as society. Study suggested that there are some concepts which can help to improve the processes work. (1) Combination of "agency theory" with "stakeholder theory" could help. (2) Elaborate "responsiveness codes of practice" which can help to incorporate relative parties in preparing, monitoring and timely amendments of codes. (3) Efforts were given to making individuals realise the consequences of their wrong actions. Every business should create atmosphere of moral ethics and values. Businesses should keep in mind that stakeholders are assets of business and follow all the codes of practice in corporate governance. Reich (2007) explored the concept of corporate social responsibility, cultural differences and ethical behaviour. Author quoted Corporate Social Responsibility as a smart management which is covered by few terms such as: morality, values and ethics. Study expresses that ethical philosophy should be there to view the actual society and communities. For companies code of ethics cultural differences must be considered and should wider the concept of organisational culture instead of natural culture. Ethical behaviour should be praised and unethical behaviour should not be tolerated. Study suggested that moral philosophies are most important assets for code of ethics so formulation of marketing ethics felt needed for the betterment of organisation and society. Marketing models should be developed for ethics and marketing activities. Andrew, Zur and John (2008) investigated the Australian retail industry, in the context of orientation of corporate social responsibility and organisational performance. This paper aims to contribute towards business ethics concept literature, through abstracting the relationship amongst corporate strategy, organisational culture and stakeholders and the establishment of a Corporate Social Responsibility orientation. Study further explored that, whether CSR procedures, policies and practices will consequence in an inclusive enhanced advantage, for the organisation and, as a result, it positively enriches organisational performance. Relationships have been examined within the framework of retail industry in Australia, concentrating on the food, clothing, textiles and footwear segments. Valentine, Sean and Gary (2009), explored some projected relationships amongst corporate social responsibility, professional ethical standards and the alleged role of ethics. Primary data was collected from 313 managers who were registered with a professional research association with the help of structured questionnaire. Questions were asked on the related topic of CSR, ethics and ethical standards. Data was analysed through Regression analysis, which showed the positive relationship between alleged professional ethical standards and the believed importance of ethics and social responsibility. A negative relationship was found between the Perception of corporate social responsibility, perceived professional ethical standards and the coordination of ethics and social responsibility. Results of the study suggested that, every profession should improve ethical standards to boost social responsibility; meanwhile these programmes and initiatives are accompanying with enriched employee principled attitude.

\section{NEED OF THE STUDY}

Corporate social responsibility is a subject and concept of anyone's interest. Now days, every person would be affected by the decisions of CSR through industries and it can also affect organisations due to lack of responsibilities, not fulfilling social obligations and vice-versa. Corporate social responsibility concept has been shifted from the traditional 
view that organisation's first priority should be maximization of wealth (Milton Friedman, 1970) ${ }^{4}$ In today's era, organisations first concern is to oblige their social, environmental and ethical responsibilities or value maximization then moves to profit and wealth maximization of firm.

Society is a mixture of consumer, employees, customers, retailers, stockholders etc. In other words, companies are the essential element or part of the society. Organisations adhere to society and cannot survive without the support of society. Thus, it is the responsibility of corporation to function in the favour of social benefits and for their own long run survival in competitive culture of the nation (Keith, 1975; Capra, 1992; Brenner, 1993; Donaldson and Preston, 1995). CSR is measured as the obligation of an enterprise towards society and other stakeholders. Corporate social responsibility is a fascinating topic or issue in modern commerce and management field. It has an impressive value in the eyes of everyone either it is stakeholders or organisations (Carroll, 1979) ${ }^{5}$ CSR makes the reputation or goodwill of any company. It is difficult to identify whether an organisation is impelled to fulfil its duties and responsibilities or adoption of ethical values and moral duties are the strategy to make reputation in front of all (Windsor, 2001) ${ }^{6}$. In this study, CSR is being a concept whereas organisations are the medium through which CSR activities have been practiced.

Corporate social responsibility and organisational culture has a positive relationship because organisations are prone to make or improve their image and it can be easily possible with the initiatives taken by firms and chequered the effect of CSR initiatives on society, stakeholders and other issues. These initiatives are beyond the legal obligations to companies. As far as the concept of business ethics is concerned it is an important factor of any enterprise because ethics expresses positive, negatives, right or wrong in the organisational context. Corporate ethics are essential for implementing CSR in the organisation in a true manner. It tells what is morally right or wrong In favour of every individual and as a whole. The notion of CSR has long been recognised in the area of research, literature and adopting this concept in the business. After reviewing the literature in the context of CSR practices, it has been observed that very large number of studies has been taken place globally, which analysed the initiatives, practices, contribution and comparative analysis in the area of CSR but the need to know the perspective of employees working in Indian companies towards CSR practices, organisational culture and business ethics prevails in their companies. Not much literature is found in the context of telecommunication industry which means there is a research gap on the concern topic which accumulates the perception, experience and observation of employees regarding these three most important factors of any company.

The main purpose of this study is to research that how impressively CSR practices are being practiced in the small and large level of companies in telecom industry having offices in Delhi and NCR. To ascertain the relationship between CSR practices and business ethics of an enterprise from the employee's perspective eventually, study will answer all the questions which arise in the mind of every stakeholder. Simultaneously it will give the real image of a company in front of their employees. It will reveal the image or reputation of the organisation from the employee perspective and can find the remedies and rectification in decisions if they harm society, employees and other stakeholders. This study will contribute in the literature of concern topic and it will also enhance the understanding and knowledge of the concepts related to research. 


\section{RESEARCH GAP}

- The essence of empirical research is being sensed in the area of Business ethics and Corporate Social Responsibilities collectively.

- Till now there is no such standard framework is available to investigate the concept of Business Ethics and Corporate Social Responsibility practices.

- No research has been taken place in the context of Business Ethics and Corporate Social Responsibility in telecom sector companies.

- Researchers either studied on CSR and Business Ethics or Telecom industry respectively. Simultaneous study of all fields identified necessary.

\section{OBJECTIVES OF THE STUDY}

The research objectives have been designed to evaluate the effect of business ethics on corporate social responsibility in telecom industry.

- To study the relationship between business ethics and its factors with CSR activities.

- To examine the relationship among the factors of business ethics and CSR practices.

- To identify the association between the study variables such as business ethics with Corporate Social Responsibility practices.

\section{RESEARCH METHODOLOGY}

Data collection period was September 2015 to June 2016. This is a cross-sectional research and it involved quantitative approaches to data collection. 20 companies were included in the sample of Telecom industry which consists of 10 large and 10 small companies. For individual employee respondents, the estimated sample size was 500 based on confidence level of $95 \%$ and confidence interval of error $+/-5 \%$ (Cohen, 2009). However, 500 questionnaires were sent out and 335 were returned in an operational form.

\section{Data Sources}

Data is collected from both primary and secondary sources. Primary sources were middle level employees of 20 companies of telecom industry in Delhi and NCR, who filled structured questionnaires. Secondary sources included academic journal's article mainly published by the Corporate Reputation Review, International and National journals of Corporate Social Responsibility and Organizational culture. Various reports and publications from Telecom Regulatory Authority of India. GRI (Global Reporting Initiative) were also studied to extract ethical dimensions and CSR related information.

For Corporate social responsibility practices has no single measure which can be used universally. For the purpose of study researcher has developed an instrument to assess CSR practices has been selected after deep discussions and took opinion of experts in the same field. Instruments have been examined for its reliability. Nineteen statements with two factors for business ethics and fifty statements with nine factors for CSR, have been developed and analysed on 5 Likert scale.

While we are selecting an appropriate scale to our study, it is important to analyse scale reliability. The main issue 
concern with the scale is internal consistency, so to check internal consistency of scale- Cronbach's alpha coefficient is used on the variables. Firstly combined reliability test of CSR practices and business ethics have initiated.

Table 1: Combined Reliability Test of CSR Practices and Business Ethics

\begin{tabular}{|c|c|}
\hline Cronbach's Alpha & N Of Items \\
\hline 832 & $50+19=69$ \\
\hline
\end{tabular}

\section{Reliability and Validity Test of CSR Practices}

Reliability test for corporate social responsibility practices is used to check the believability and credibility of the study. Reliability of the scale is recognized by Cronbach's alpha $(\alpha)$. The reliability coefficient using Cronbach's alpha is highly significant at 0.938 and Through Guilford's formula of validity which is the square root of reliability coefficient and it also yielded a high validity coefficient at 0.968 .

Table 2: Reliability Test of Corporate Social Responsibility Practices

\begin{tabular}{|c|c|}
\hline Cronbach's Alpha & N of Items \\
\hline 938 & 50 \\
\hline
\end{tabular}

\section{Reliability and Validity Test of Business Ethics}

Reliability test for business ethics variable is used to check the uniformity and credibility of the findings in this present study. Reliability of the scale is recognized by Cronbach's alpha $(\alpha)$. The reliability coefficient using Cronbach's alpha is also highly significant at 0.868 and it was found by the formula of Guilford's (1954) validity and yielded a high validity coefficient at 0.931 .

Table 3: Reliability test of Business Ethics

\begin{tabular}{|c|c|}
\hline Cronbach's Alpha & N of items \\
\hline 868 & 19 \\
\hline
\end{tabular}

\section{Hypothesis of the Study}

- $\mathbf{H}_{\mathbf{0}} \mathbf{1}$ : There is no significant relationship among business ethics and its factors with CSR practices.

- $\mathbf{H}_{\mathbf{0}} \mathbf{2} \quad$ : There is no significant relationship between the factors of business ethics and CSR practices.

\section{DATA ANALYSIS AND INTERPRETATION}

Data has been analysed through different statistical tools namely: Spearman's Rank Correlation, Chi Square analysis, Regression analysis and these tools have been done on each dependent (Corporate Social Responsibility) and independent variable (Business Ethics).

\section{Features and Distribution of Sample}

The data is collected from employees working at the middle level management in small and large level companies of telecom industry in Delhi and NCR.

Table 4: Distribution of Sample According to Gender and Types of Company

\begin{tabular}{|c|c|c|c|}
\hline Gender & Small & Large & Total \\
\hline Male & 87 & 97 & 184 \\
\hline Female & 75 & 76 & 151 \\
\hline Total & $\mathbf{1 6 2}$ & $\mathbf{1 7 3}$ & $\mathbf{3 3 5}$ \\
\hline
\end{tabular}


Above data shows the distribution of samples (Telecom company employees) according to the gender and types of company. Table shows that out of total 335 respondents, 162 belong to small companies and 173 belong to large companies of Telecom Industry. Out of 162 employees from small companies 87 are male and 75 are female employees and out of 173 employees from large companies 97 are male and 76 are female employees. Both type of respondents (male and female) have somehow equally participated in the process.

\section{Correlation Analysis}

Correlation Analysis explains the relationship between two variables, There can be Positive relationship (+), Negative relationship (-) and No relationship (0) between variables. Present study uses Spearman's Rank Correlation test to analyse the relationship between Independent and Dependent Variable.

Correlation Analysis between Independent Variable (Business Ethics) and Dependent Variable (Corporate Social Responsibility)

To examine the relations between independent variables such as organizational culture and business ethics and their factors with corporate social responsibility and its factors, Spearman's Rank Correlation method is applied and associations between variables is measured accordingly

Table 5: To Assess the Relationship between Business Ethics and Corporate Social Responsibility Practices of Telecom Companies (Small and Large) in Delhi and NCR

\begin{tabular}{|l|c|c|}
\hline \multicolumn{1}{|c|}{ Variables of the Study } & Business Ethics & $\begin{array}{c}\text { Corporate Social } \\
\text { Responsibility }\end{array}$ \\
\hline Business ethics & +1.000 & - \\
\hline Corporate social responsibility & $0.655^{* *}(0.000)$ & +1.000 \\
\hline
\end{tabular}

It further displays that there is a positive correlation between Corporate Social Responsibility and Business Ethics $\left(\mathrm{r}=0.655^{*}\right)$ The result supported by the study of Kirti Shiva Kumar (2005) that, there is a positive correlation between Corporate Social Responsibility and Business Ethics and another study by Reich (2007) stated that, "Corporate Social Responsibility is nothing more than a nifty management, covered in the language of morality and ethics".

Table 6: Relationship between overall Responses of Corporate Social Responsibility and Factors of Business Ethics

\begin{tabular}{|l|l|l|c|c|}
\hline \multicolumn{1}{|c|}{ S. No } & \multicolumn{1}{|c|}{$\begin{array}{c}\text { Business Ethics } \\
\text { Factors }\end{array}$} & Small & Large & Combined \\
\hline I & Attitude & $0.412 * *(0.000)$ & $0.777 * *(0.000)$ & $0.640 * *(0.000)$ \\
\hline II & Practice & $0.346^{* *}(0.000)$ & $0.734 * *(0.000)$ & $0.614 * *(0.000)$ \\
\hline
\end{tabular}

*Significant at 0.05 level (2 tailed) Values in Parenthesis () indicates P-value

Table 6 shows that, there is a high degree of (+ve) positive correlation between overall response of Corporate Social Responsibility Practices and factors of Business Ethics, in Small and Large Telecom Companies in Delhi and NCR.

Table 7: Relationship among Overall Response of Business Ethics and Business Ethics Factors of Sample Group in Telecom Industry

\begin{tabular}{|c|c|c|c|}
\hline \multirow{2}{*}{$\begin{array}{c}\text { Factors of Business } \\
\text { Ethics }\end{array}$} & \multicolumn{3}{|c|}{ Correlation (P) Among Business Ethics And Its Factors } \\
\hline & Attitude & Practice & Business Ethics \\
\hline Attitude & 1.000 & & \\
\hline Practice & $0.815^{* *}(0.000)$ & 1.000 & \\
\hline Business Ethics & $0.934 * *(0.000)$ & $0.968 * *(0.000)$ & 1.000 \\
\hline
\end{tabular}


The above table reveals the results, between overall results of Business Ethics and Factors of Business Ethics and it shows that all values are highly significant at $(\mathrm{p}<0.05)$ highest correlation is found between the factor of Business Ethics Practice and overall response of Business Ethics $(r=0.968)$ and in between Attitude and overall response of Business Ethics is $(\mathrm{r}=0.934)$. There is also a high positive correlation between the factors attitude and Practice $(\mathrm{r}=0.815)$.

The result clearly shows that all score of factors of Business Ethics (Attitude and Practice) and overall response of Business Ethics are highly significant and positive. Therefore, $\mathrm{H}_{0}$ (Null Hypothesis) is rejected at $(\mathrm{p}<0.05)$ and $\mathrm{H}_{1}$ (Alternate Hypothesis) is accepted. Eventually the factors of business ethics and Overall response on business ethics are highly significant and positive. This study supported by the theory of Duane Windsor (2006) that "Ethical responsibility theory advocates strong corporate self-restraint and altruism duties and expansive public policy strengthening stakeholder rights". Hence the results say that ethicality in business is a first step to moving forward towards the success.

The objective of the study is to find out the relationship between the Corporate Social Responsibility (Dependent Variable) and factors of Business Ethics and (Independent Variable) in small and large companies of Telecom Industry so it is rational to find out the relationship between overall response of Corporate social responsibility and factors of Business Ethics. The analysis shows that all correlation values are positive and highly significant that there is a significant relationship between the overall response of Corporate Social Responsibility and factors of Business Ethics. It reveals the positive correlation values which are: Attitude $(\rho=640)$, Practice $(\rho=0.614)$

\section{Regression Analysis (OLS) Ordinary Least Square}

The data obtained were fitted to the equation by the regression method. The relationship between (Dependent) Corporate Social Responsibility and (Independent variables) Organisational Culture \& Business Ethics were determined and inferences were drawn on the basis of regression analysis. Regression Analysis on Corporate Social Responsibility practices and Business Ethics of Telecom Companies in Delhi and NCR

Bivariate Regression Model Equation

$\mathrm{Y}=\alpha+\beta \mathrm{X}^{\prime} \mathrm{s}+$

Where $\alpha=$ intercept

$\beta$ is the slope of the beta coefficient

$\mathrm{Y}$ is the dependent variable (Corporate Social Responsibility)

Table 8: Regression Analysis on CSR Practices with Business Ethics in Telecom Companies

\begin{tabular}{|c|c|c|c|c|}
\hline Factors & Constant (A) & Beta (B) & F-Value & Adjusted $\mathbf{R}^{2}$ \\
\hline $\begin{array}{ll}\text { BUSINESS } & \text { ETHICS } \\
\left(\mathrm{X}_{\mathrm{B}}\right) & \end{array}$ & $100.51(0.000)$ & $1.264(0.000)$ & $250.34 *(0.000)$ & 0.427 \\
\hline
\end{tabular}

Significant at $1 \%$ level ( 2 tailed) Values in Parenthesis () indicates P-value

The above table 8 presents the results of bivariate linear regression model where the effect of Business Ethics is examined on Corporate Social Responsibility. Results of the study found that Business Ethics has significant and positive relationship with Corporate Social Responsibility (p-value close to 0.0000). The magnitude of change is 0.427 , which means $1 \%$ change in Business Ethics will cause a change of $42.7 \%$ in Corporate Social Responsibility. 
Scatter Plot Diagram of Regression Analysis of Corporate Social Responsibility on Business Ethics in Telecom Industry

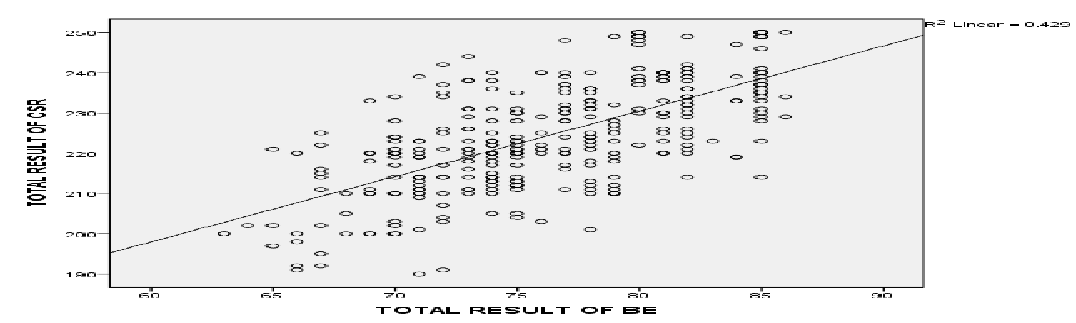

Figure 6.1: Regression Analyses of CSR Practices on Business Ethics

The value of adjusted $\mathrm{R}^{2}$ is 0.427 means $42.7 \%$ of variation in Corporate Social Responsibility is explained by Business Ethics alone. (Where P-value<0.01). Hence, it can be concluded that Business Ethics in telecom industry leads to improvement in their Corporate Social Responsibility. The value of adjusted $\mathrm{R}^{2}$ is 0.427 means $42.7 \%$ of variation in Corporate Social Responsibility is explained by Business Ethics alone. (Where, P-value<0.01). Hence, it can be concluded that Business Ethics in telecom industry leads to improvement in their Corporate Social Responsibility.

\section{CONCLUSIONS}

Telecom industry is contributing profoundly in the GDP of India and it is also fascinating industry to study. Being world's second largest industry telecommunication sector is performing commendable job for their subscribers and stakeholders holistically. The study was aimed to know the influence of Business Ethics on Corporate Social responsibility practices by telecom companies with the help of two factors. Results unveils that the large level companies of telecom industry have highest correlation between overall response of Corporate Social Responsibility practices and the Attitude factor of Business Ethics. It means attitude of employees being a part of business ethics is playing a vital role in the organisation which outspread ethical behaviour among employees. Out of CSR factors, organisational profits and implementation structure showed the highest association that means employees of these organisations believed that if CSR policies and strategies implementing perfectly then it will increase organisational profits in the long run. The crux of whole study expresses that, there is positive influence of business ethics on corporate social responsibility practices of telecom companies. Value-added and positive business ethics will lead to enhanced and improved corporate social responsibility practices and initiatives.

\section{Recommendations and Suggestions for Future Research}

- Business Ethics expresses morality among the employees and towards the organisation so these practices should extended in the organisational activities.

- Ethics does not belong to the organisation, it belongs to an individual. Business ethics are universal in nature so it is the responsibility of organisation to exercise these activities in the organisation.

- Every company either its small or large should include CSR reports in company's Annual report to make their company fair and transparent in every context.

- Sustaining corporate social responsibility practices properly increases goodwill of company and customer can also rely on the quality of products and services as well. 
- Company's employees are the main assets and stakeholders of the company, so companies should take their participation in decision making process, proper maintenance of hygiene and sanitation in the premises of company, which will bring sense of belongingness in employees towards their company.

- Another industry can be taken to collect sample size.

- Variables can be different for the study. Values, morality, Principles, Rules of Conduct and Standards (of Behaviour) etc. can be chosen instead of taking Business Ethics.

- Sample size can be increased for more appropriate results to make the representatives of the universe.

\section{REFERENCES}

1. Andrew Zur and Jody Evans, (2008), "CSR orientation and organizational performance in the Australian retail industry", Melbourne Business School,Kerrie Bridson, Deakin University

2. Bahl E., (2014) An Overview of CSR Rules Under Companies Act, 2013.

3. Bird F., Smucker J., (2007), The Social Responsibilities of International Business Firms in Developing Areas, Journal of Business Ethics, 73, p. 1-9.

4. Carroll, A. B. (1979). A three-dimensional conceptual model of corporate performance. Academy of management review, 4(4), 497-505.

5. Davis, K., \& Blomstrom, R. L. (1971). Business, society, and environment.

6. Donaldson, J., Fafaliou, I. (2003) Business ethics, Corporate social responsibilities and corporate governance: A review and summary critique. European Research Studies, 6(1-2).

7. Dunfee Thomas W; Smith N. Craig and Ross William T., (1998), "Social Contracts and Marketing ethics", A working Paper in INSEAD, France. Economy, 78(2), 193-238.

8. Friedman, M. (1970). A theoretical framework for monetary analysis. journal of Political Economy.

9. Gautam R., Singh A., CSR practices in India: A Study of Top 500 Companies. GBMR-2 (1) 41-56.

10. Ghalambaz S., Ghalambaz S., (2012) Investing the relationship between Ethics, Values and Organisational Commitment Among Telecommunication Managers in Isfahan Province, Iran. International Journal of Multidisciplinary Science and Engineering. 3 (7).

11. Gupta \& Kasana (2017). Organisational Culture and its Impact on Corporate Social Responsibility: A Statistical Validation, Asian Journal of Research in Business Economics and Management, Vol. 7, No. 8, pp. 310-323.

12. Hopkins M., 2003 the Planetary Bargain-CSR Matters, Earth scan: London.

13. Hunt, S. D., Wood, V. R., \& Chonko, L. B. (1989). Corporate ethical values and organizational commitment in marketing. The Journal of Marketing, Vol. 53 (July) 79-90.

14. Juliet Altham, (2006), 'Business Ethics versus Corporate Social Responsibility: Competing or Complementary Approaches? International Business Ethics Review, International Business Ethics Institute, www. business-ethics. org. presented at the International conference on commerce at Chennai, India.

15. Kumar N., (2014) An Analysis of Impact and Challenges in India. Abhinav International Journal of Research in Management and Technology, 3 (5). 
16. Lunheim R.,(2006) CSR Research Seminar, April 25th-26th 2006, Hosted by Department of Industrial Economics and Technology Management, NTNU.

17. Martin, K., E., Mulcahy, A., M. (2000). Innovation, Ethics and business. Bridge paper, Business Roundtable Institute for corporate ethics.

18. Michael Hopkins, (2003),The Planetary Bargain-CSR Matters, London, Earth-scan, UK Minister for Corporate Social Responsibility.

19. Reich, B. H. (2007). IT alignment: what have we learned?. Journal of Information technology, 22(4), 297-315.

20. Robin, D. P., \& Reidenbach, R. E. (1987). Social responsibility, ethics, and marketing strategy: Closing the gap between concept and application. The Journal of Marketing, 44-58.

21. Robin, Donald, P., \& Reidenbach, R., E. (1987). Social responsibility, ethics and marketing strategy: closing the gap between concept and application. Journal of marketing, 51(1), 44-58.

22. Sethi S. P., (1975), Dimensions of corporate social performance: an analytical framework. California Management Review. 17. (3). Spring. 58-64.

23. Srivastava K. A., Negi G., Mishra V., Pandey S., (2012) CSR: A Case Study of TATA Group, IOSR Journal of Business and Management 3 (5), 17-27.

24. Ubius U., Alas R., (2009) Organisational Types as Predictors of CSR, Engineering Economics, 61 (1): 90-99.

25. Valentine, Sean and Gary, (2009), "Professional Ethical Standards, Corporate Social Responsibility, and the Perceived Role of Ethics and Social Responsibility,” Journal of Business Ethics; Oct2008, Vol. 82 Issue 3, p657-666.

26. Ward H., Fox T., (2002) Public Sector Roles in Strengthening Corporate Social Responsibility: A Baseline Study. The World Bank CSR Practice.

27. White Louis P and Rhodeback Melanie J., (1992), "ethical Dilemmas in Organization Development: A cross cultural analysis”, Journal of Business, Vol. 19, Pp. 211 to 224.

28. White, L. P., \& Rhodeback, M. J. (1992). Ethical dilemmas in organization development: A cross-cultural analysis. Journal of Business Ethics, 11(9), 663-670.

29. Windsor, D. (2001). The future of corporate social responsibility. The international journal of organizational analysis, 9(3), 225-256.

30. www. trai. gov. in 
